\title{
OBSERVATIONS ON THE CLINICAL COURSE AND TREATMENT OF ONE HUNDRED CASES OF STILL'S DISEASE
}

BY

\author{
B. E. SCHLESINGER, C. C. FORSYTH, R. H. R. WHITE, J. M. SMELLIE and C. E. STROUD \\ From The Hospital for Sick Children, Great Ormond Street and University College Hospital, London
}

(RECEIVED FOR PUBLICATION MARCH 23, 1960)

Just over 60 years have elapsed since Still's (1897) classical description of rheumatoid disease in children, yet, despite extensive study, the pathogenesis remains obscure. To include it in a composite group of 'collagen' disorders may ultimately help to solve the problem of aetiology, as certain of the histological changes are common to them all. On the other hand there are many discrepancies. Those, for instance, who point to a close affinity between rheumatic and rheumatoid disease in childhood find it difficult to ascribe the latter to an allergic process involving a streptococcal infection. Then there is the extraordinary decline in the incidence of acute rheumatism in this country over the past 50 years (Cox and Schlesinger, 1956), which has by no means been reflected in our experience in the case of Still's disease.

The only apparent advance has been in treatment; steroid therapy has a dramatic effect in both these diseases, as it has to a lesser extent in other 'collagen' disorders. Some believe that any improvement is merely temporary, and the view has been put forward that results in the treatment of these diseases are as good with high doses of aspirin as with cortisone (Medical Research Council and American Heart Association Joint Report, 1955; Joint Committee Reports of the Medical Research Council and Nuffield Foundation, 1954, 1955, 1957a; Ansell, Bywaters and Isdale, 1956).

An assessment of the long-term effect of steroids in rheumatoid arthritis in children has been one of the main purposes of this investigation and our conclusions differ from those of Ansell et al. (1956). One hundred cases have been followed for up to 15 years at The Hospital for Sick Children, Great Ormond Street, and at University College Hospital, London, and recent personal examination, or in a very few instances reports from their local doctors, have brought their progress up to date. The account which follows is divided into two parts. One deals with the course and complications observed in the series as a whole, in the hope that something further may be learned of the natural history of the disease. The other gives the findings in the 63 children who received steroids, showing the immediate and eventual results of treatment.

\section{PART I: CLINICAL}

\section{Course and Complications}

Age at Onset. Still's disease is well known to occur earlier than acute rheumatism. In the group we are considering of 60 girls and 40 boys the most frequent age of onset was well below 5 years, and the incidence of first attacks declined sharply in the second decade (Fig. 1).

Mode of Onset. Still's disease compared with rheumatoid arthritis in adults generally runs a much more acute course, quite often affecting many parts of the body before settling in the joints. The main features in these circumstances may be high fever, rash, lymphadenopathy and leucocytosis, with only an occasional ache in the limbs. Such children may, therefore, suffer many investigations to exclude other diseases, and a variety of antibiotics are often given in vain. It is generally at this early stage that obvious or insidious pericarditis and pneumonitis can occur. Eighteen children in the series behaved in this manner. The average interval between systemic and arthritic involvement in this group was four months. In one patient the interval was much longer, three years, and in another there were four separate bouts of fever before the nature of the disease became clear.

Fever. If the disease is left to run its natural course, pyrexia may persist for a long time, even for years. The fever may also assume a peculiar 


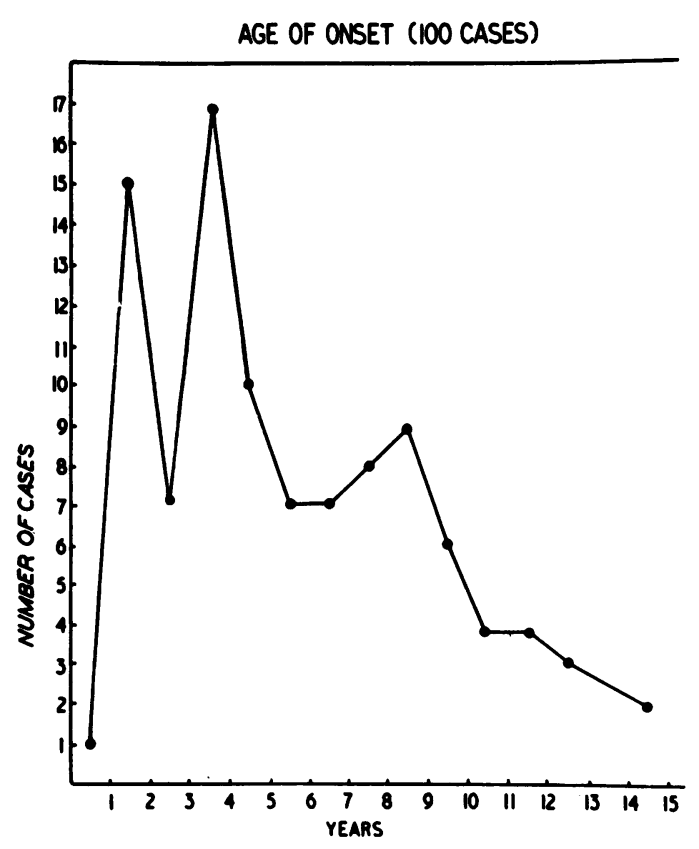

FIG. 1.-Age at onset of symptoms in 100 cases of Still's disease.

periodicity, but the temperature chart shows greater irregularity than in Hodgkin's disease and brucellosis (Schlesinger, 1949). Sometimes the fever is very high, the child feels extremely ill, vomiting is frequent and the condition becomes serious. It is under such circumstances that steroids are particularly effective, but the dose may have to be large and the course of treatment prolonged to keep the fever and other symptoms under control.

Rash. A rash occurred in about $40 \%$ of patients. It is a feature which helps in the diagnosis of an obscure case. Only rarely is it present without an associated lymphadenopathy and leucocytosis. It resembles erythema annulare of acute rheumatism in its wide distribution and in the way it comes and goes, unaffected by any form of treatment (Fig. 2). It may be a sign of an extensive systemic rheumatoid disorder and yet does not necessarily carry a gloomy prognosis.

A rash was the main presenting sign in five cases, with varying degrees of fever and lymphadenopathy. Joint involvement was limited to a transient arthralgia with little or no swelling. These children have been followed for four to six years. None have developed arthritis; three are now quite well, but two have a persistent rash and slight malaise.

Skin biopsy of the rash demonstrated coarse oedematous collagen fibres with abnormal staining properties and perivascular cellular infiltration in the upper portion of the corium, with polymorphs and, to a lesser extent, lymphocytes, plasma cells and histiocytes predominating (Fig. 3). Sometimes the rash is appreciably elevated and has an urticarial quality, and rarely it is purpuric, when patches of skin show purple striae or even gangrenous lesions, leaving beneath a healthy healing area (Figs. 4 and 5).

Leucocytosis. A leucocytosis of up to $30,000 /$ c.mm. with 80 to $90 \%$ neutrophil polymorphs, is a well-known phenomenon, chiefly encountered at a florid stage of the disease. It occurred in $44 \%$ in our series. This reaction was investigated by Schlesinger and Cathie (1951), and a marked increase of granulocyte cells was discovered in the bone marrow, with a shift to the left. This leucocytic reaction may easily lead to an erroneous diagnosis of osteomyelitis, or of suppurative arthritis, when a single joint only is at first involved.

Occasionally in severe cases the bone marrow seems to become exhausted by continuous stimulation and a profound pancytopenia develops.

Effect of Trauma. In an appreciable number, 14 in the present series, arthritis began in the very joint which had suffered a minor injury shortly before. Selye might interpret this as a locus minoris resistentiae, reacting to generalized systemic stress otherwise insufficient to affect healthy tissues. It might equally well be the result of some local circulatory damage, such as is thought to precipitate bone tuberculosis or osteomyelitis in similar circumstances.

Lymphadenopathy. This is a sign of systemic rather than of arthritic involvement and bears no regional relationship to the joints involved. The glands can be greatly enlarged in the absence of arthritis, and gross arthritis may proceed eventually to crippling without lymphadenopathy at any stage. The epitrochlear and axillary glands are the most likely to become easily palpable. Biopsy has not revealed more than reactive hyperplasia. Eventually with remission of the disease the glands resume their normal size. Splenomegaly occurs less frequently.

Arthritis. The type of joint involvement in Still's disease is so well known that further description would be superfluous. Possible delay in the appearance of arthritis in the course of the disease has already been sufficiently emphasized. Quite often a fleeting arthralgia or transient periarticular swelling precedes the onset of more chronic poly- 


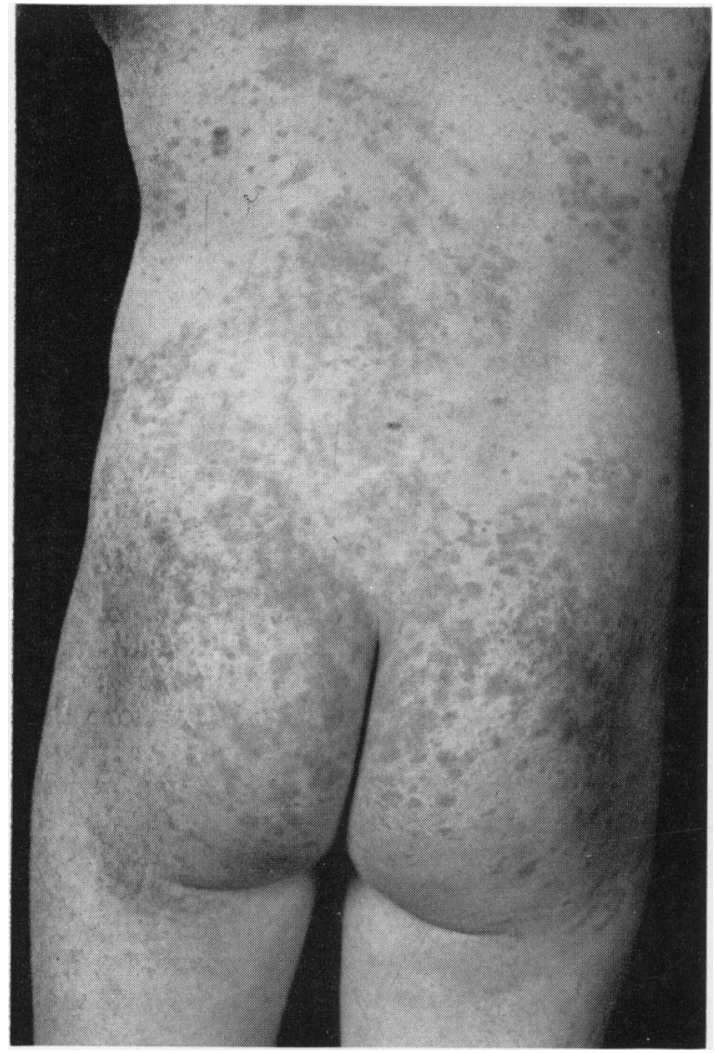

Fig. 2.-Rheumatoid rash in a girl of 7 years with other signs of systemic involvement.

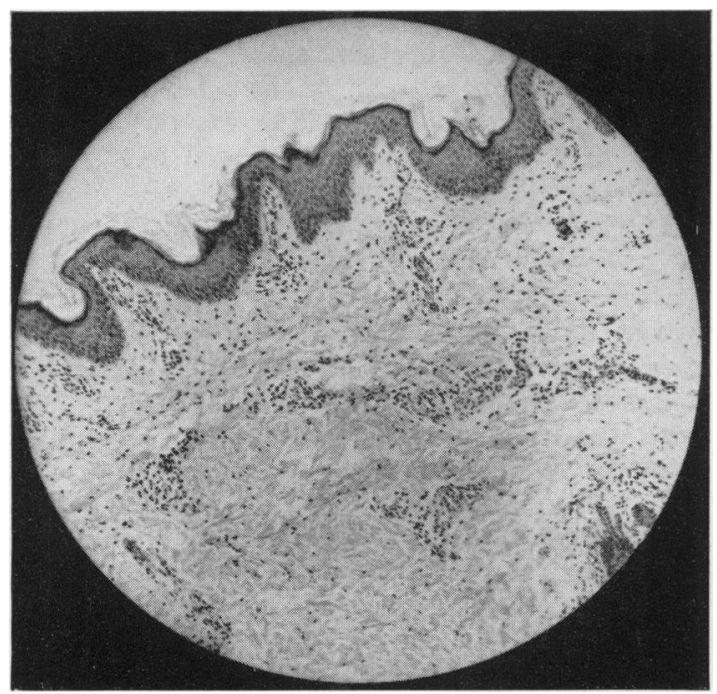

FIG. 3.-Histological picture of a skin biopsy in the region of a rheumatoid rash. $(\times 58$.

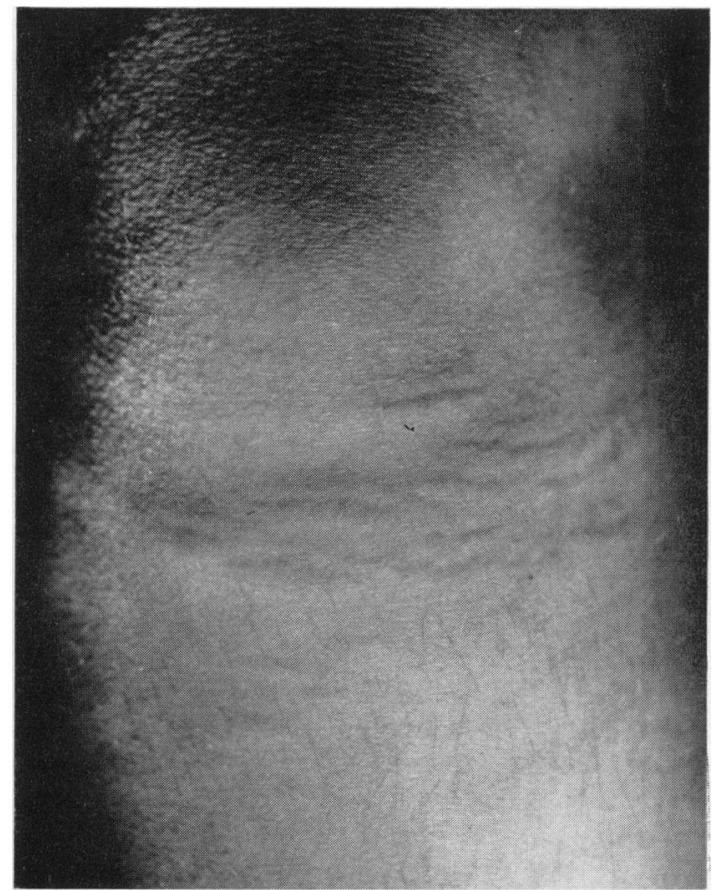

FIG. 4.-Purple striae above the knee in a girl aged 10 years with severe rheumatoid disease.

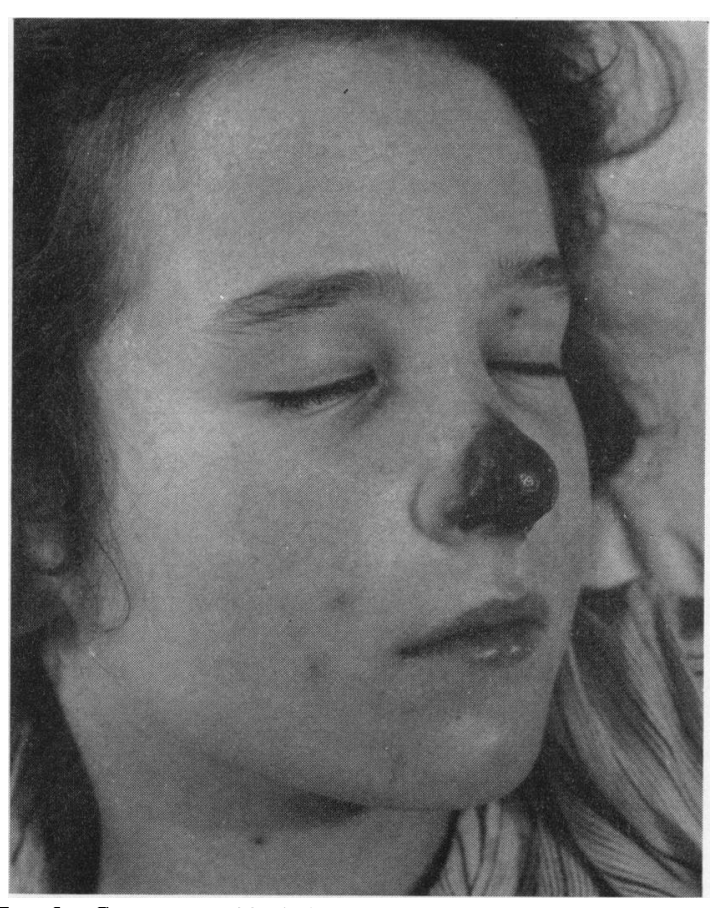

Fig. 5.-Gangrenous skin lesion over the nose in the same child (c.f. Fig. 4), which finally healed completely. 
arthritis. This does not mean that joint lesions cannot be the predominant feature from the very beginning. The disease in children often takes the adult form, but even then there may be an unusual course. The spine is frequently affected, particularly in the cervical region, and neck stiffness is commonly an early manifestation. When this is part of a generalized arthritis the interpretation is clear but if, as in three of our children, the trouble is at first confined to the neck, causing severe torticollis, the diagnosis may present difficulty.

It is helpful to divide arthritis into 'wet' and 'dry' types, depending on the amount of inflammatory exudate. With large effusions the joint cartilage is offered some protection, and there is much less pain and hardly any protective spasm. In our experience the chance of eventual complete healing is then far greater, provided the capsule has not been so widely stretched as to allow subluxation to occur. The outlook in the 'dry' variety is not so good, for the joint surfaces easily become eroded, adhesions form and muscle spasm ends in contractures. Although finally the disease may burn itself out, the child may be left a complete cripple with ankylosis or superimposed osteo-arthritis.

The sudden appearance of monarticular arthritis in one of the larger joints instead of the usual symmetrical distribution, which usually includes the smaller joints, may lead to confusion. With this mode of onset an infection such as suppurative arthritis or tuberculosis is naturally suspected and treated accordingly. The fate of the three patients who presented in this manner serves as a warning. One had had his hip explored, the second received anti-tuberculous drugs for three months and the third was immobilized in plaster for an appreciable period, before the true nature of the illness became apparent.

Another type of arthritis has been termed intermittent hydrarthrosis. In this variety, of which there have been five examples in our series, the knees became distended with fluid at irregular intervals. The swelling persisted for a few weeks or many months and then disappeared spontaneously. The skin temperature over the joints was normal; there was no pain and the movements were not greatly impaired. Fever was usually absent, lymphadenopathy and leucocytosis were not observed, and the sedimentation rate was normal or slightly raised. A rash was present in only one case, and this was urticarial and atypical. Intermittent hydrarthrosis has long figured in the literature (Cohen, 1955) and its aetiology is still debated. The disorder in children should always be regarded as a possible forerunner of rheumatoid arthritis later in life, and the histology of a synovial biopsy may demonstrate changes compatible with this disease. Moreover, in four of our five patients other joints subsequently became involved, although not seriously, and there was pain and limitation of movement. The final outcome is shown in Table 1 . Three of the children have had no recurrence for nine years or more and are well; in the other two there is some disability which, in one case (E.S.), is kept under control with steroids.

Laryngeal Stridor. Arthritis of the crico-arytenoid joints has been described in long-standing rheumatoid arthritis in adults, causing stridor, dyspnoea and cyanosis (Hart and MacKenzie, 1955; Copeman, 1957; Baker and Bywaters, 1957; Pearson, 1957; Manning, 1957). We have been unable to discover any account of this occurring in children, but the present series includes three instances. Hoarse, laryngeal, inspiratory stridor was noticed, which became so alarming in one child that tracheotomy had to be performed after laryngoscopy had demonstrated 'paralysed' cords. The condition eventually resolved on cortisone and did not recur when this treatment was stopped.

Pericarditis. In his original description Still emphasized the importance of recognizing pericarditis. It may be obvious at the very outset and bear close resemblance to that occurring in rheumatic fever, the child being very ill, although endocarditis is not detected and myocarditis is less in evidence. More often it is insidious and overshadowed by the high fever, extreme malaise, vomiting and extensive polyarthritis. Pleuropneumonic signs may also be present. For instance, in one child who died of bulbar poliomyelitis a year after the onset of her rheumatoid disease, autopsy revealed unsuspected obliterative pericarditis and pleurisy.

It might be imagined that pericarditis augurs ill for the child's future, as it so often does in rheumatic fever, but this does not necessarily follow. In the present series, apart from the case already mentioned, one other child with clinical pericarditis died, but four others with this complication were all perfectly well when re-examined several years later. Although two are left with limited joint disability, none of them have any detectable cardiac disease and they are able to lead active lives. The favourable result in three of these children may have been due to steroid therapy given systemically. In one case it was injected into the pericardium. The fact that pericarditis in Still's disease is not usually associated with endocarditis and myocarditis must also have some bearing on the prognosis. 
TABLE 1

INTERMITTENT HYDRARTHROSIS

\begin{tabular}{|c|c|c|c|c|}
\hline Patient & $\begin{array}{c}\text { Age at Onset } \\
\text { (yrs) }\end{array}$ & Total Duration & Result & $\begin{array}{c}\text { Age at Last Examination } \\
(y r s)\end{array}$ \\
\hline $\begin{array}{l}\text { C.G. } \\
\text { E.T. } \\
\text { P.S. } \\
\text { S.T. }\end{array}$ & $\begin{array}{r}9 \\
10 \\
2 \\
5\end{array}$ & $\begin{array}{l}2 \\
4^{\frac{1}{2}} \\
6\end{array}$ & \multirow{2}{*}{$\begin{array}{l}\text { Complete recovery } \\
\text { Complete recovery } \\
\text { Complete recovery } \\
\text { Recurrence after one } \\
\text { year's intermission } \\
\text { Recurrence after five } \\
\text { years' intermission }\end{array}$} & $\begin{array}{l}12 \\
12 \\
13 \\
12\end{array}$ \\
\hline E.S. & 5 & 10 & & $\begin{array}{l}12 \\
15\end{array}$ \\
\hline
\end{tabular}

Irido-cyclitis. This is fortunately a rare complication. It occurred in five patients in our series. Although local and systemic steroids appear to render the uveitis less active, vitreous and corneal opacities may form eventually and a cataract can develop. In this event surgery is not very satisfactory. Vision therefore becomes seriously impaired, even though arthritis may disappear entirely. One unfortunate boy in this group, now aged 19, was originally treated with gold, but has become a hopeless cripple, and has had to undergo enucleation of one eye because of this serious complication.

Lenoch, Králík and Bartoš (1959) questioned a true relationship between iridocyclitis and rheumatoid arthritis in adults. In Still's disease there is no doubt about this eye complication, which we observed in $5 \%$ of our cases and Ansell and Bywaters (1959) noted in $7 \%$ of theirs.

Amyloid Degeneration. This complication has been described in long-standing adult rheumatoid arthritis. Fortunately it is seldom encountered in children, but it occurred once in our series and has also been reported by Forsyth (1960) associated with calcification of the digital vessels. Our case, a boy with Still's disease at 18 months, developed albuminuria at the age of 5 years. The Congo red test was positive and a gland biopsy revealed amyloid changes. A further gland biopsy repeated six years later was normal. His arthritis improved after repeated intra-articular injections of hydrocortisone, and now at the age of 15 he plays rugby football, boxes and is leading a normal school life. There is minimal limitation of movement of the hips and shoulder joints, and the blood sedimentation rate is normal, but some albuminuria persists $(200 \mathrm{mg}$./ $100 \mathrm{ml}$.). He has improved remarkably from a complication which is generally considered to have a very poor prognosis.

Muscular Abscess. The muscles in Still's disease usually escape the general inflammatory process; in fact all that is seen is wasting, depending on the degree of arthritis and immobilization. Acute inflammation of the soft tissues with swelling of the limb must therefore be a rare and remarkable complication. One such patient has been observed, in whom a lump in the biceps became necrotic and incision liberated a quantity of sterile pus. At this stage the child was critically ill with high fever, but made a spectacular recovery on cortisone. Now one year later his arm is normal in size and function, while arthritis of the knees and ankles remains. The pathogenesis of such lesions is obscure, but they may be areas of degenerating intramuscular nodular formation (Curtis and Pollard, 1940; Steiner, Freund, Leichtentritt and Maun, 1946; Kersley, Barber, Cregan and Gibson, 1954).

Nodules and Bone Erosions. Nodules are a wellrecognized feature in rheumatoid arthritis and they were found in seven children. Three of them are now quite well with no disability; three still suffer, from a 'smouldering' arthritis and one died. One child, now 12 years of age, still has nodules, although she is otherwise well and is studying ballet dancing. The nodules have persisted for nine years, except for an intervening period of two years, during which they could not be detected.

Nodules are commonly subcutaneous, but they may be present in other regions. Possibly the following case is an example of nodules in bone. A girl of 6 years complained of pain and stiffness in the shoulder joints and cervical spine. Rash, adenopathy, pyrexia and moderate leucocytosis followed and the sedimentation rate was raised. One month later painless lumps were noticed on the forehead and over the occiput. Radiography of the skull revealed a number of irregular areas of bone destruction, not only in the region of the soft tissue swellings, but also scattered about in the parietal bone (Figs. 6 and 7). After numerous investigations had failed to reveal the nature of the lesions, a bone biopsy demonstrated a condition suggestive of a collagen disorder (Fig. 8). Steroid 


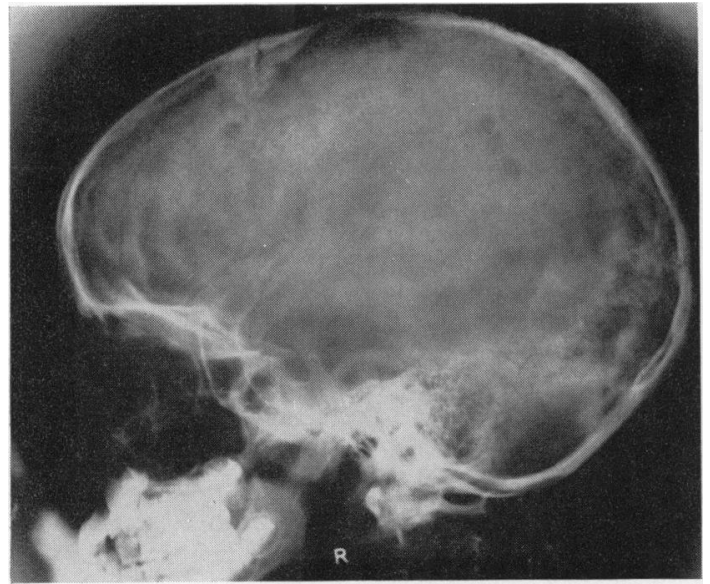

FIG. 6.-Radiograph of the skull of a girl, 7 years of age, with mild rheumatoid disease, showing irregular areas of bone destruction.

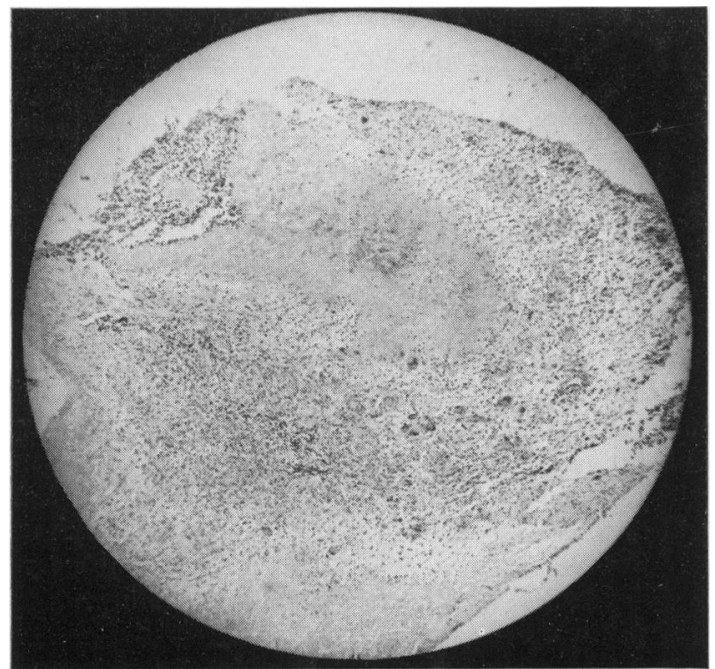

FIG. 8.-Histology of swollen subcutaneous tissue in the vicinity of the skull erosions depicted in Fig. 6. Degeneration of collagen can be seen with fibrinoid changes and the appearance of epithelioid cells and fibroblasts. $(\times 35$. $)$

therapy caused the soft tissue swellings and the skull erosions to disappear, but twice there was a recurrence of both a few months after the treatment was stopped. On each occasion the skull radiograph returned to normal following a further course of steroids. Cystic bone lesions in rheumatoid arthritis have also been described by Mather (1954) and by Silver and Steinbrocker (1954).

Associated Collagen Disorders. With full knowledge of the clinical similarity between Still's disease,

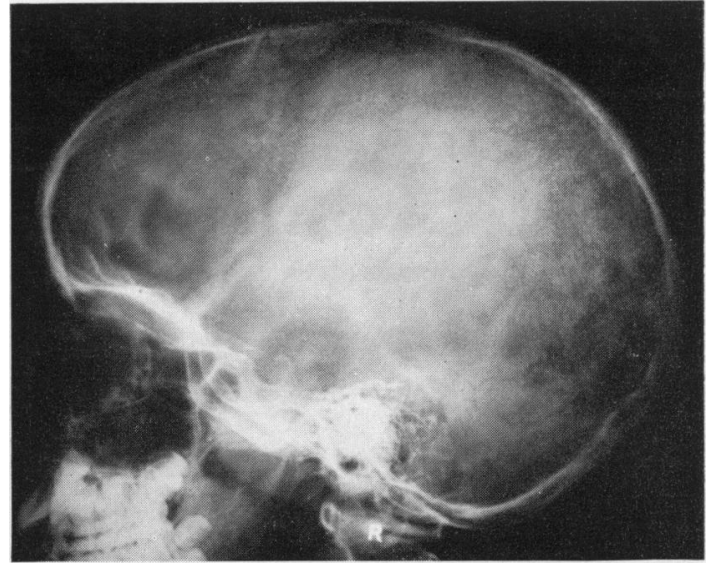

FIG. 7.-Radiograph of the skull of the same child (c.f. Fig. 6) two months later after steroid therapy.

disseminated lupus erythematosus, polyarteritis nodosa and dermatomyositis, considerable care has been taken in selecting cases for this review. L.E. cells are difficult to find, but when they have been demonstrated that case has been excluded. Muscle biopsy, carried out in some instances, has also helped in the differential diagnosis.

Dermatomyositis was present in three of the children with Still's disease. In addition to the usual joint signs of rheumatoid disease, complicated in one instance by pericarditis and pleurisy, the children's hands appeared cyanosed, and telangiectases were visible in the nail beds and along the gum margins. In two, subcutaneous nodules were present, which on biopsy revealed rheumatoid changes. In all three children the skin and subcutaneous tissues had the thickened, non-pliable character of dermatomyositis, and this was confirmed in one by muscle and skin biopsy. Leucocytosis was not a feature, although the sedimentation rate was raised and there was ample evidence of general systemic involvement. Re-examined four to nine years from the onset, two of these children are quite well and attending school with little or no residual arthritis, and the third is happily at work despite some restricted movement of the joints. Curious reddish 'collodion' patches are still present on the knuckles of one child.

Associated Rheumatic Disease. Despite reports of the association of rheumatoid and rheumatic disease, this occurred in only one of the 100 cases, a boy of 9 years who developed chorea and carditis after rheumatoid arthritis had been present for 
five months. He is now 14 years old and well without having had steroid therapy.

\section{PART 2: TREATMENT}

Rest followed by physiotherapy and graded activity form the basis of treatment for rheumatoid arthritis. Spontaneous remission on this regime may occur quite early. This, however, may not be maintained and after remaining free of symptoms for some months, 11 children in our total series suffered a relapse. Under such circumstances, or when simple measures fail, steroid therapy should be considered. In view of the disappointing reports of cortisone treatment in rheumatoid arthritis in adults (Joint Committee Reports, 1954, 1955, 1957a) and in children (Ansell et al., 1956), it is important to record the good results obtained from steroids in the present series.

\section{Steroid Therapy}

Dosage. Sixty-three patients were studied, 60 of whom received steroids systemically and three by intra-articular injection alone. The majority were given oral cortisone, but some had A.C.T.H. injections and latterly prednisolone was used in preference to cortisone. The dosage of steroid and the duration of treatment depended upon the patient's response and upon the time taken for the disease to become inactive. The initial dosage was high, namely in the region of $200 \mathrm{mg}$. of cortisone by mouth daily for a period of at least a week. During the following two weeks it was gradually reduced to about $100 \mathrm{mg}$. daily and this dose was continued until the arthritis was well controlled. The child was then allowed up for increasing periods, and further reductions of cortisone were cautiously made until a maintenance level was reached below which symptoms recurred or there was a sharp rise in blood sedimentation rate. This was usually in the region of 50 to $75 \mathrm{mg}$. daily. It was found that severe relapses often occurred if each successive drop in dosage was too great or too rapidly undertaken. Maintenance therapy was usually continued for several months at least, and finally it was possible to taper off the steroid treatment entirely without provoking a relapse. In some instances, a short course of A.C.T.H. was given at this stage to stimulate the suprarenal glands, although this precaution was probably unnecessary provided the cortisone was withdrawn sufficiently gradually.

Delay in Treatment. Our figures show to a striking degree the importance of instituting steroid therapy during the first six months of the disease if optimal results are to be obtained (Table 2). Indeed, all of the 18 children so treated progressed favourably; 16 were perfectly normal and two were only slightly disabled once the attack had subsided and steroids had been withdrawn.

Duration of Treatment. Analysis of the 63 cases who received steroid therapy shows that three had intra-articular cortisone only, five died and four were taken off steroids for various reasons while the disease was still active. These cases are omitted from Table 3, which gives the total duration of treatment for the 38 patients in whom a remission of the disease took place and for the 13 patients still on treatment when the follow-up was completed. Among the 38 patients who had been treated with steroids on a dosage indicated above and for periods mentioned in Table $3,32(84 \%)$ had a remission of their disease within one year of starting therapy and a further four, totalling $36(95 \%)$ within 18 months. No further steroids have been given to those 38 children, but the fact that 13 patients are still maintained on this treatment demonstrates that sometimes much longer courses are required. For example, one boy has now been on steroids for eight years as relapse occurred every

TABLE 2

DELAY IN SYSTEMIC STEROID TREATMENT AND FINAL DISABILITY: 38 CASES IN REMISSION

\begin{tabular}{|c|c|c|c|c|c|c|c|}
\hline \multirow{2}{*}{\multicolumn{3}{|c|}{$\begin{array}{c}\text { Final Disability } \\
\text { Following } \\
\text { Remission }\end{array}$}} & \multirow{2}{*}{ No. } & \multicolumn{4}{|c|}{ Time Before Steroid Treatment } \\
\hline & & & & $<6 \mathrm{mths}$ & $<\overline{1 \text { yr }}$ & $<2$ yrs & $>2$ yrs \\
\hline $\begin{array}{l}\text { None } \\
\text { Slight } \\
\text { Moderate } \\
\text { Severe }\end{array}$ & $\begin{array}{l}\cdots \\
\cdots \\
\cdots\end{array}$ & $\begin{array}{l}\ldots \\
\ldots \\
\ldots \\
\ldots\end{array}$ & $\begin{array}{r}24 \\
9 \\
3 \\
2\end{array}$ & $\begin{array}{r}16 \\
2 \\
0 \\
0\end{array}$ & $\begin{array}{l}4 \\
1 \\
1 \\
0\end{array}$ & $\begin{array}{l}3 \\
1 \\
0 \\
1\end{array}$ & $\begin{array}{l}1 \\
5 \\
2 \\
1\end{array}$ \\
\hline
\end{tabular}

TABLE 3

DURATION OF SYSTEMIC STEROID TREATMENT

\begin{tabular}{|c|c|c|}
\hline \multirow{2}{*}{$\begin{array}{c}\text { Duration of } \\
\text { Treatment }\end{array}$} & \multicolumn{2}{|c|}{ No. of Cases } \\
\hline & In Remission & Still on Steroids \\
\hline $\begin{array}{l}=2 \mathrm{mths} \\
=4 \mathrm{mths} \\
=6 \mathrm{mths} \\
=8 \mathrm{mths} \\
-10 \mathrm{mths} \\
-12 \mathrm{mths} \\
=1 \frac{1}{2} \mathrm{yrs} \\
=2 \mathrm{yrs} \\
=3 \mathrm{yrs} \\
=4 \mathrm{yrs} \\
=7 \mathrm{yrs} \\
-8 \mathrm{yrs}\end{array}$ & $\begin{array}{l}7 \\
7 \\
7 \\
5 \\
1 \\
5 \\
4 \\
- \\
2 \\
-\end{array}$ & $\begin{array}{l}\frac{1}{2} \\
\frac{1}{1} \\
3 \\
2 \\
1 \\
1 \\
1\end{array}$ \\
\hline Totals & 38 & 13 \\
\hline
\end{tabular}

* Many have been on treatment for a considerable time and the outcome is uncertain. 
TABLE 4

TIME SINCE COMPLETION OF SYSTEMIC STEROID TREATMENT

\begin{tabular}{|c|c|}
\hline $\begin{array}{c}\text { Time Since } \\
\text { Completion (yrs) }\end{array}$ & $\begin{array}{l}\text { No. of Cases } \\
\text { in Remission }\end{array}$ \\
\hline $\begin{array}{l}-1 \\
-3 \\
-5 \\
-7\end{array}$ & $\begin{array}{r}7 \\
16 \\
6 \\
9\end{array}$ \\
\hline Total .. & 38 \\
\hline
\end{tabular}

TABLE 5

PRESENT STATUS OF $60^{*}$ CHILDREN GIVEN SYSTEMIC STEROIDS

\begin{tabular}{|c|c|c|c|c|c|}
\hline \multirow{2}{*}{\multicolumn{2}{|c|}{$\begin{array}{c}\text { Disability } \\
\text { of } \\
\text { Joints }\end{array}$}} & \multicolumn{2}{|c|}{ Remission } & \multicolumn{2}{|c|}{ Active } \\
\hline & & Nos. & $\%$ & Nos. & $\%$ \\
\hline $\begin{array}{l}\begin{array}{l}\text { None } \\
\text { Slight } \\
\text { Moderate } \\
\text { Severe }\end{array} \quad . . \\
\end{array}$ & $\begin{array}{l}. \\
\therefore \\
\therefore\end{array}$ & $\begin{array}{r}24 \\
9 \\
3 \\
2 \\
\end{array}$ & $\begin{array}{r}60 \cdot 5 \\
23 \cdot 8 \\
10 \cdot 5 \\
5 \cdot 2 \\
\end{array}$ & $\begin{array}{l}3 \\
6 \\
4 \\
4 \\
\end{array}$ & $\begin{array}{l}17 \cdot 6 \\
35 \cdot 2 \\
23 \cdot 5 \\
23 \cdot 5\end{array}$ \\
\hline Total & .. & 38 & & $17 \dagger$ & \\
\hline
\end{tabular}

* Five children are dead.

t Thirteen of the 17 active cases are still under treatment with steroids, in one because iritis is still troublesome, although there is no arthritic disability.

time the dose was reduced below a critical level. The duration of treatment required in any individual child cannot be foretold and does not depend upon the severity of the initial manifestations. The fact that 18 months' treatment was adequate for the majority of the children contrasts with the years of treatment usually required in adults (Joint Committee Reports, 1954, 1955, 1957a). This difference in response is of great practical importance. More than one course was also necessary in some children to deal with recurrences of their disease several months or even years after steroid therapy was stopped. After five years' remission, however, relapses were unusual and Table 4 should be studied with these reservations. This Table gives the time that has elapsed since the child ceased to have steroid treatment and has remained well.

Results of Steroid Therapy. Steroid therapy produced some improvement within a week in the majority of children treated. The erythrocyte sedimentation rate usually fell to normal in about two to three weeks and the children were then allowed up. In many the effect of the drug was dramatic. Fever quickly subsided and the child's appetite and well-being improved. The lymph glands and the spleen, if enlarged, diminished in size, and a rapid decrease in joint pain and swelling led to improved mobility. Signs of pericarditis in a few children disappeared and recovery took place. Anaemia was gradually corrected without the necessity for blood transfusions. Only the skin rash proved resistant to treatment and continued intermittently after other manifestations of the disease had been controlled. With steroid therapy there was little doubt that the acute phase of the disease became much more tolerable and, while this in itself was gratifying, the long-term results were even more important. By modifying joint stiffness and sweiling it proved possible to prevent serious permanent damage in the majority of children. The present status of the children treated with steroids systemically is seen in Table 5 . In the 63 children treated systemically or locally, 41 have completed their steroid treatment (Table 6) and $35(85 \%)$ of these are normal or show only slight residual joint damage. Seventeen patients still have active disease;

TABLE 6

COMPARATIVE SERIES

\begin{tabular}{|c|c|c|c|c|c|c|c|c|c|c|c|c|c|c|c|c|}
\hline \multirow{3}{*}{ Series } & \multirow{3}{*}{ Treatment } & \multirow{3}{*}{ No. } & & & & & & & \multicolumn{8}{|c|}{ Final Disability: Cases in Remission } \\
\hline & & & \multicolumn{2}{|c|}{ Died } & \multicolumn{2}{|c|}{ Active } & \multicolumn{2}{|c|}{$\stackrel{\text { In }}{\text { Remission }}$} & \multicolumn{2}{|c|}{ None } & \multicolumn{2}{|c|}{ Slight } & \multicolumn{2}{|c|}{ Moderate } & \multicolumn{2}{|c|}{ Severe } \\
\hline & & & No. & $\%$ & No. & $\%$ & No. & $\%$ & No. & $\%$ & No. & $\%$ & No. & $\%$ & No. & $\%$ \\
\hline $\begin{array}{lll}\text { Present } & \ldots & \ldots \\
\text { Present } & \ldots & \ldots\end{array}$ & $\begin{array}{l}\text { No steroid therapy* } \\
\text { Steroid therapy }\end{array}$ & $\begin{array}{l}37 \\
63 \dagger\end{array}$ & $\begin{array}{l}2 \\
5\end{array}$ & $\begin{array}{l}5 \\
8\end{array}$ & $\underset{17}{2}$ & $\begin{array}{r}5 \\
27\end{array}$ & $\begin{array}{l}33 \\
41\end{array}$ & $\begin{array}{l}90 \\
65 .\end{array}$ & $\begin{array}{l}18 \\
25\end{array}$ & $\begin{array}{l}55 \\
61\end{array}$ & $\begin{array}{l}10 \\
10\end{array}$ & $\begin{array}{l}30 \\
24\end{array}$ & $\begin{array}{l}3 \\
4\end{array}$ & $\begin{array}{r}9 \\
10\end{array}$ & 2 & $\begin{array}{l}6 \\
5\end{array}$ \\
\hline & Total & 100 & 7 & 7 & 19 & 19 & 74 & 74 & 43 & 58 & 20 & 27 & 7 & 9 & 4 & 5 \\
\hline Colver (1937) & No steroid therapy & 49 & 12 & 24 & 18 & 36 & 19 & 38 & \multicolumn{4}{|c|}{$11(58 \%)$} & \multicolumn{4}{|c|}{$8(42 \%)$} \\
\hline $\begin{array}{c}\text { Ansell and Bywaters } \\
\text { (1959) }\end{array}$ & $\begin{array}{l}\text { Steroid therapy in } \\
63\end{array}$ & $\begin{array}{c}(216) \\
\text { assess- } \\
\text { ment in } \\
209\end{array}$ & 9 & 4 & 105 & 50 & 95 & 46 & 42 & 44 & & & $53(5$ & $5 \%)$ & & \\
\hline
\end{tabular}

* Compared with those on steroid therapy in the present series the majority of these cases were less severely affected.

+ Includes three who received intra-articular therapy alone. 
13 of them are on steroid therapy at present and the outcome is uncertain.

Five children died, two due to generalized rheumatoid disease with pericarditis and three from intercurrent infections. One of the two children, who died with pericarditis, relapsed after steroid therapy was stopped (in 1951) more abruptly than would now be recommended, and the other was not responding to a moderate dose of steroid when she died. With regard to fatal infections, one child developed bulbar poliomyelitis at a time when her Still's disease was well controlled with A.C.T.H.; her case was fully reported at the time by Pugh (1952). Another child died suddenly at home of bronchopneumonia following measles one month after hormone therapy had been stopped, and the third succumbed to infective hepatitis while on cortisone.

Intra-articular hydrocortisone has in some cases helped to clear up persistent joint effusions when given alone or in conjunction with oral cortisone. Two out of three children with joint effusions but no systemic signs who were treated with intraarticular injections responded promptly. A $25 \mathrm{mg}$. injection given twice proved effective, but in the third child this had to be repeated many times before the effusion in the knee joint responded. Some relief lasting six to eight weeks has been reported by Chandler, Wright and Hartfall (1958) from this method of treatment in adult cases. However, in spite of clinical improvement the joints deteriorated radiologically, possibly due to 'a damaging level of performance by interference with a normal, locally protective mechanism' (Chandler and Wright, 1958). In the two children just mentioned where this method succeeded the joints were clinically and radiologically normal six months and three years later respectively.

Toxic Effects of Hormones. Children receiving high dosage or prolonged steroid therapy should be protected against possible electrolyte disturbances by the administration of potassium chloride, 1 to 2 g. daily. A high protein and limited carbohydrate diet is also desirable in view of the protein loss produced by steroids. In face of the increased appetite it is difficult to reduce the total calorie intake, although amphetamine may be of some assistance. Prevention of obesity obviously helps to minimize the strain put on weight-bearing joints. It is well known that infections may be masked by steroids. Oral penicillin (phenoxymethyl penicillin, $125 \mathrm{mg}$. b.d.) may help to prevent the more common pyogenic disorders and should be prescribed daily.
These were the routine supportive measures adopted in the majority of cases and no serious electrolyte disturbance occurred. There was no undue tendency towards minor infections, and none developed tuberculosis. One child, however, contracted pneumonia and empyema following measles and made a complete recovery. The three deaths from infections have already been noted.

Euphoria was fairly common and in some ways was an advantage in helping the child to cope with a long illness. None of the children became depressed, as has been described in adult patients on steroid therapy. No significant glycosuria was noted and symptoms suggestive of peptic ulceration were not encountered. Hypertension occurred in two boys, necessitating the withdrawal of steroid therapy, after which the blood pressure returned to normal.

Osteoporosis due to cortisone affects the whole skeleton, but is most noticeable in the vertebral column. Involvement of the lower thoracic and the lumbar vertebrae occurred in eight children, $12.7 \%$ of those who had been treated with steroids, with associated deformity in five. One had spondylitis at the onset of his illness, which may have contributed to the osteoporosis, but in the other seven it was certainly due to steroid therapy. This complication, originally mentioned by Welch and Forsyth (1953), has been considered by Luder (1954), and was observed in two children by Ansell et al. (1956), although it was not referred to in adult trials (Joint Committee Reports, 1954, 1955, 1957a). When vertebrae were affected, it was thought desirable to keep the children ambulant to prevent further decalcification resulting from bed rest. In every instance recalcification occurred satisfactorily after withdrawal of cortisone and no neurological complications occurred. For example, one boy who developed vertebral collapse after a seven months' course of cortisone was able to play cricket for his school four years later and now at the age of 19 has a perfectly normal vertebral column with no evidence of permanent damage (Fig. 9a and b).

Routine x-ray examination of the spine every few months in children on long courses of hormone therapy was instituted in order to detect the complication early, and it was usual to reduce the steroid dosage, or stop it altogether, if increasing osteoporosis was found. It was noticed that children who already suffered from generalized skeletal decalcification due to enforced immobilization before steroid therapy were especially liable to vertebral collapse in a comparatively short period after treatment had begun. A high protein diet, 


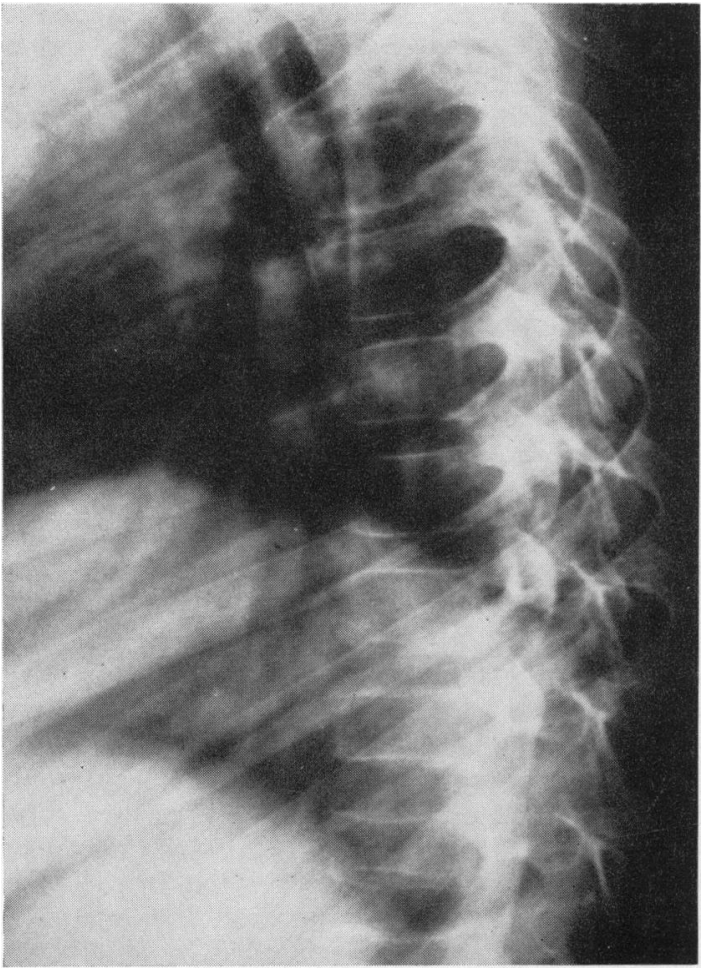

FIG. 9a.-Radiograph showing osteoporosis and vertebral collapse in a boy aged 12 after seven months' treatment with steroids.

extra calcium and vitamin $D$ cannot be relied upon to prevent this complication. The use of testosterone or its analogues has also proved disappointing. Our experience with triamcinolone in a few cases has not shown it to be superior in this respect.

\section{Other Forms of Drug Therapy}

Phenylbutazone proved too toxic when tried in a few patients and mepacrine and chloroquin had no effect. Chrysotherapy was not used because of its known toxicity, but it should be mentioned that two children treated by a colleague improved considerably with gold therapy following only partial relief with steroids.

Many of the children received aspirin in ordinary analgesic dosage. Ten were given higher doses of aspirin ( 1 grain per $1 b$. body weight per day), such as are sometimes employed in the treatment of acute rheumatic fever. This treatment was carried on for two weeks in nine children and four months in one without noticeable benefit. In three, clinical salicylism occurred with tinnitus, deafness, vomiting and acidosis, but despite this the blood sedimentation rates were above $50 \mathrm{~mm}$./hr. and the joints remained

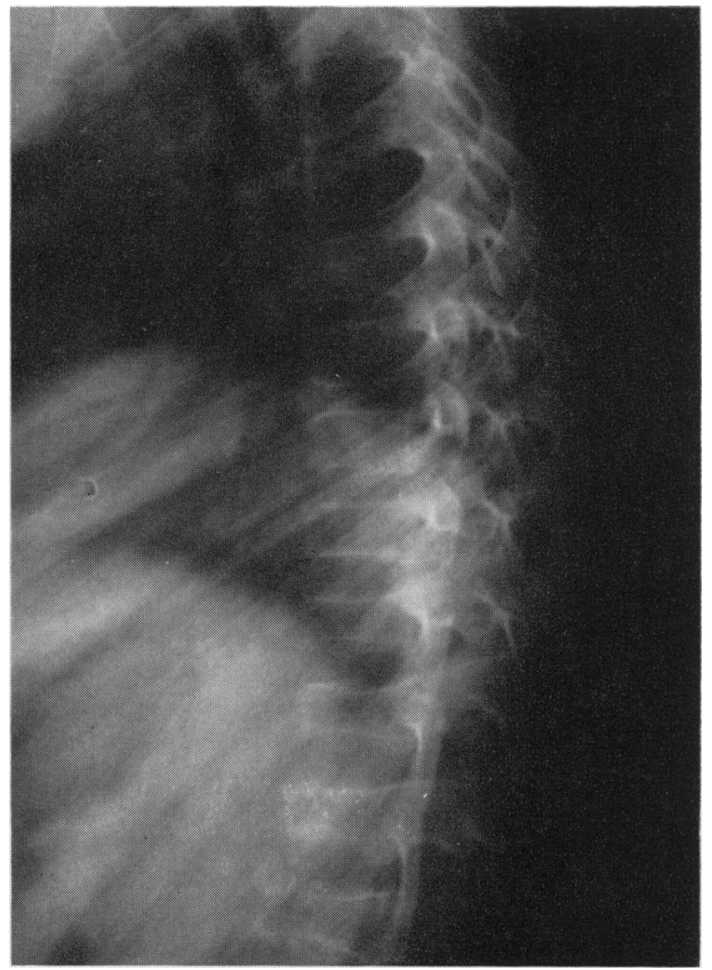

FIG. 9b.-Radiograph of the spine seven years later (c.f. Fig. 9a) demonstrating that these lesions are no longer present.

swollen and painful. Another child developed severe bleeding due to salicylates. In our experience even high doses of aspirin failed to produce in any child the direct beneficial effect on the swelling and stiffness of the joints seen with steroid therapy.

\section{DISCUSSION}

This study confirms Still's original contention that the disorder in childhood often has its major impact on various sites of the body apart from the joints. It is indeed the inflammatory process in these tissues which provokes such an acute reaction and, if allowed to progress, it may eventually prove fatal. It has been shown that systemic involvement can in fact continue for a considerable time before arthritis becomes the most arresting feature, and that this has often delayed a correct diagnosis.

Both in its earlier age of onset and more isolated attack on one part of the heart, the pericardium, Still's disease is in marked contrast to rheumatic fever. But there are several points of similarity, such as nodules, the behaviour of the rash, the effect of trauma and the benefit obtained from 
steroids. It is therefore surprising that rheumatic and rheumatoid manifestations were only once associated in the 100 cases. Other collagen disorders, however, were present at the same time in several.

Although Still believed that cases in which the joints alone were affected were not in the same category as the disease he described, our experience indicates that they can be regarded as a variant of the same disorder. We have seen that in many children there may be a 'systemic' stage followed by an 'arthritic' stage, but in a number the disease can begin insidiously in the joints, as it usually does in adults. Finally, adults occasionally fall ill with all the manifestations of the acute generalized onset most common in childhood. The first to describe this was Chauffard, a contemporary of Still.

Taking all these possibilities into consideration, there is no doubt that the malady is more acute in children than in adults and yet the period of activity of the disease is often very much shorter. For example, out of 60 patients in our series who were given systemic steroids, remission took place in at least $53 \%$ within one year of starting therapy. In the joint clinical trial of the Medical Research Council and the Nuffield Foundation (Joint Committee Report, 1957a) the remission rate in 53 adults treated with cortisone was only $23 \%$ over three and a half years. For the child with rheumatoid arthritis, therefore, a limited course of hormones may prevent permanent disability without incurring the dangers associated with years of steroid treatment.

Some writers believe that large doses of aspirin are as good as steroid therapy in the control of rheumatoid arthritis, and that the side-effects of steroids make their use undesirable. We have not found even high doses of aspirin to be nearly as effective as adequate steroid therapy. In the joint clinical trials of the Medical Research Council and the Nuffield Foundation (Joint Committee Reports, $1954,1955,1957$ a), in which it was concluded that cortisone was not superior to aspirin in the treatment of early rheumatoid arthritis in adults, the average dose of cortisone was on the whole much lower relative to the weight of the patient than that used in our series of children, where the amount was determined by the effect on the disease. It seems likely that success with steroids depends upon adequate dosage maintained over a sufficient period. In the Medical Research Council trial of 1954 (Joint Committee Reports, 1954) it was observed that a number of patients relapsed when steroids and aspirin were withdrawn rapidly after 12 weeks' treatment, whereas both drugs afforded greater relief when they had been given for one year or more.

Prednisone used in relatively higher doses in adults gave better results (Joint Committee Reports, 1957b), and the most recent trial (Joint Committee Reports, 1959) shows definite benefit from the use of prednisolone compared with aspirin or other analgesics. In the group treated with prednisolone a decrease in the incidence and progression of radiological signs of erosive joint disease was apparent. These findings are in favour of prednisolone being used in preference to cortisone. A trial combining prednisolone with corticotrophin is being carried out and may prove to be the best method in those cases requiring prolonged steroid therapy (Savage, Davis, Chapman, Wickings, Robertson and Copeman, 1959).*

In our experience, aspirin in high dosage has produced toxic effects including tinnitus, deafness, acidosis, vomiting and bleeding. As has already been pointed out, the one important side-effect of steroid therapy in our series was osteoporosis, affecting eight children out of the 60 treated systemically. This risk, however, was considered justifiable in view of the danger of death or severe crippling if the rheumatoid disease was left uncontrolled. Moreover, the vertebral lesions disappeared if steroids were stopped or their dosage reduced appreciably.

The results of treatment, both conservative and with steroids in our series of 100 children are given in Table 6. Although detailed records of the 37 children who were not given steroids are available and show a high remission and recovery rate, they cannot be used for comparison because they were not selected at random. Moreover, they were milder cases and this was the main reason they were only given symptomatic treatment. 'Historical' controls are also unsatisfactory, but, nevertheless, the results in our more severe cases treated with steroids are much better than those reported by Colver (1937), using the general measures, which were all that were available at that time. Deaths are now much less common and there are many more complete recoveries.

Sixty-three of our 100 children were given steroids. Ansell and Bywaters (1959) have reported 216 children with rheumatoid arthritis, of whom 63 were treated with steroids, i.e. about half the proportion as compared with our series. Fewer remissions were reported in their patients and the percentage

\footnotetext{
* Recently we have been successfully using this method of combining oral prednisolone with daily ACTH gel intramuscular injections. By this means a lower satisfactory total dosage of steroids is required and cortical adrenal atrophy is less likely to occur.
} 
who had no final disability once the disease was no longer active was also smaller (Table 6). It is tempting to speculate that our apparently better results were due to the more frequent use of steroid therapy.

These comparisons are admittedly open to criticism. Nevertheless, clinical experience has convinced us of the value of steroid therapy when serious systemic disease or severe joint disturbances persist after several weeks' trial of conservative measures. The present study of 100 children with this disorder suggests that this therapy will have to be considered in about two-thirds of the cases.

\section{SUMMARY}

The most important systemic features and complications of Still's disease are described in addition to unusual types of arthritis, which may obscure the diagnosis.

Some support is given to the conception that rheumatoid arthritis is only one of a group of collagen disorders by the association in certain instances of Still's disease and dermatomyositis in the same patient.

Treatment with steroids gives the best results if begun early. The duration of treatment required is much shorter in children than in adults. Osteoporosis with vertebral collapse is the most serious complication of steroid therapy. Although a few recalcitrant cases pursue a relentless course in spite of all forms of treatment, steroid therapy is justified in all but mild forms of the disease and is most likely to bring about complete recovery.

Our thanks are due to the many colleagues who have allowed us to follow up their patients and to the practitioners who have given us up-to-date information about a few of the children. We are grateful to Dr. Martin Bodian for his histological reports and to Mr. Derek Martin for the photographs.

\section{REFERENCES}

Ansell, B. M. and Bywaters, E. G. L. (1959). Prognosis in Still's disease. Bull. rheum. Dis., 9, 189.

, and Isdale, I. C. (1956). Comparison of Cortisone and Aspirin in treatment of juvenile rheumatoid arthritis. Brit. med. J., 1, 1075.
Baker, O. A. and Bywaters, E. G. L. (1957). Laryngeal stridor in rheumatoid arthritis due to crico-arytenoid joint involvement. lbid., 1, 1400 .

Chandler, G. N. and Wright, V. (1958). Deleterious effect of intraarticular hydrocortisone. Lancet, $2,661$.

-, and Hartfall, S. J. (1958). Intra-articular therapy in rheumatoid arthritis. Ibid., 2, 659.

Cohen, H. (1955). The rarer arthritic syndromes. In Textbook of the Rheumatic Diseases, Ed. W. S. C. Copeman, 2nd ed., p. 276. Livingstone, Edinburgh.

Colver, T. (1937). The prognosis in rheumatoid arthritis in childhood. Arch. Dis. Childh., 12, 253.

Copeman, W. S. C. (1957). Rheumatoid arthritis of the cricoarytenoid joints. Brit. med. J., 1, 1398.

Cox, P. J. N. and Schlesinger, B. E.'(1956). The changing picture of juvenile rheumatism. Gt Ormond Str. J., No. 11, 38.

Curtis, A. C. and Pollard, H. M. (1940). Felty's syndrome; its several features, including tissue changes, compared with other forms of rheumatoid arthritis. Ann. intern. Med., 13, 2265.

Forsyth, C. C. (1960). Calcification of the digital vessels in a child with rheumatoid arthritis. Arch. Dis. Childh., 35, 296.

Hart, F. D. and MacKenzie, D. H. (1955). Pulmonary rheumatoid disease. Brit. med. J., 2, 890.

Joint Committee Reports of the Medical Research Council and Nuffield Foundation (1954). Clinical trials of Cortisone, A.C.T.H. and other therapeutic measures in chronic rheumatic diseases. Ibid., 1, 1223.

- (1955). A Comparison of Cortisone and Aspirin in the treatment of early cases of rheumatoid arthritis. Ibid., 2, 695.

(1957a). Clinical trials of Cortisone, A.C.T.H. and other therapeutic measures in chronic rheumatic diseases. Ibid. therapeutic

(1957b). A comparison of Cortisone and Prednisone in treatment of rheumatoid arthritis. Ibid., 2, 199

(1959), Clinical trials on Cortisone, ACTH and other therapeutic measures in chronic rheumatic diseases. Ann. rheum. Dis., 18, 173.

Kersley, G. D., Barber, H. S. Cregan, J. C. F. and Gibson, H. J. (1954) Degenerative rheumatoid changes. J. Bone Jt Surg., 36B, 238.

Lenoch, F., Králik, V. and Bartos, J (1959). 'Rheumatic' iritis and iridocyclitis. Ann. rheum. Dis., 18, 45.

Luder, J. (1954). Vertebral collapse after Cortisone therapy. $G$ Ormond Str. J., No. 7, 15.

Manning, D. P. (1957). Rheumatoid arthritis of crico-arytenoid joints. Brit. med. J., $2,104$.

Mather, H. G. (1954). Unusual rheumatoid arthritis (arthritis mutilans). Proc. roy. Soc. Med., 47, 457.

Medical Research Council and American Heart Association Join Report (1955). Treatment of acute rheumatic fever in children. A cooperative clinical trial of A.C.T.H., Cortisone and Aspirin. Brit. med. J., 1, 555.

Pearson, J. E. G. (1957). Rheumatoid arthritis of the larynx. Ibid., 1 , 1047 .

Pugh, R.C. B. (1952). Poliomyelitis, with myocarditis, complicating Still's disease. Gt Ormond Str. J., No. 4, 118 .

Savage, O., Davis, P. S., Chapman, L., Wickings, J., Robertson, J. D. and Copeman, W. S. C. (1959). Corticotrophin (ACTH) in rheumatoid arthritis. Ann. rheum. Dis., 18, 100.

Schlesinger, B. E. (1949). Rheumatoid arthritis in the young. Brit. med. J., 2, 197.

- and Cathie, I. A. B. (1951). Effect of Still's disease on the haemopoietic system. Ann. rheum. Dis., 10, 412.

Silver, M. and Steinbrocker, O. (1954). Resorptive osteopathy in inflammatory arthritis.' 'Absorptive arthritis', 'Opera glass hand'. Bull. Hosp. Jt Dis. (N.Y.), 15, 211.

Steiner, G., Freund, H. A., Leichtentritt, B. and Maun, M. E. (1946) Lesions of skeletal muscles in rheumatoid arthritis: nodular polymyositis. Amer. J. Path., 22, 103.

Still, G. F. (1897). On a form of chronic joint disease in children. Med.-chir. Trans., 80, 47.

Welch, R. G. and Forsyth, C. C. (1953). Still's disease treated with ACTH and Cortisone. Gt Ormond Str. J., No. 5, 1. 
lapped, so that in any one pancreas, there were islets in more than one stage.

1. Stage of budding islets: In the third and fourth gestational month, islets consisting of a central cluster of $B$ cells surrounded by ungranulated cells and occasional L cells, budded off from the ducts. The B cells predominated.

2. Bipolar Stage: From the fifth to eighth month, bipolar islets were seen, with the $B$ cells at the tip and the L cells at the base (nearest the duct).

3. 'Mantle-islet' Stage: The proliferating L cells grew round the B cells to form 'mantle-islets' with a kernel of $B$ cells and a shell of $L$ cells. The $L$ cells now greatly outnumbered the B cells. 'Mantle-islets' dominated the picture from the sixth month onward.

4. Stage of Mature Islets: From the eighth month, a few islets were seen with the haphazard distribution of L and B cells characteristic of the mature adult islet.

A point of particular interest in these observations was the presence of differentiated $L$ and $B$ cells in the islets of the smallest ( $34 \mathrm{~g}$.) foetus.

Douglas BaIn (Edinburgh). Mast cells were obtained from the tissue culture of a tumour from a newborn infant. The tumour was multifocal and undifferentiated.

G. S. Anderson and T. Bird (Newcastle). 'Congenital Iodopyrine (Felsol) Goitre.' Evidence recently presented by Morgans and Trotter (1959) strongly suggests that Felsol, a drug commonly taken by asthmatics, may be goitrogenic due to the iodopyrine it contains. Two infants (binovular twins) with congenital goitres, born of a mother with asthma and a goitre considered to be due to Felsol, were presented. One infant died at 10 hours with a thyroid of $11 \mathrm{~g}$. showing large irregular vesicles filled with colloid but with signs of epithelial activity. The other twin died at 38 days with a thyroid weighing $7 \mathrm{~g}$. showing small vesicles, poorly filled with colloid and a flat epithelium. It was suggested that the iodides liberated from iodopyrine in the maternal gut crossed the placenta to block the iodine-binding power of the foetal thyroids. Since Felsol was withdrawn nine days before delivery the histology was con- sidered to support the view that iodides caused a colloid type of goitre, but that epithelial activity soon occurred when iodides were stopped. Neither death was attributable to the goitres.

\section{REFERENCE}

Morgans, M. E. and Trotter, W. R. (1959). Jodopyrine as a cause of goitre. Lancet, 2, 374.

K. M. Lawrence (Cardiff). 'Sarcoma of Pelvis.' A large pelvic tumour that had invaded the bladder and grown along the inferior vena cava; it was thought to be an embryonic sarcoma, possibly a rhabdomyosarcoma originating from the prostate.

H. B. MARSDEN (Manchester). 'Metachromatin Leucodystrophy.' A male child with a normal sibling began to have attacks of pyrexia at the age of 16 months. He eventually lost the use of his arms and legs, developed opisthotonos and died after repeated fits at the age of 2 years 10 months. The E.C.G. showed generalized dyspolicythuria and the C.S.F. had a protein level of $100 \mathrm{mg}$. \%.

At necropsy the brain appeared relatively normal to the naked eye, but showed extensive gliosis of the white matter. Sudanophilic material was minimal and present only as small perivascular collections.

On staining with toluidine blue abundant metachromatic material was present in the brain, peripheral and spinal nerves, kidneys and to a lesser degree, in the liver, pancreas and adrenal medulla. Clinical analysis of the brain (Professor J. N. Cunningham) revealed loss of phospholipid and cholesterol with increase of hexosamine in the white matter. Numerous needle-shaped crystals were found in the adrenal cortex.

J. L. EMERy (Sheffield). 'Congenital Hypothyroidism - presenting clinically as intestinal obstruction.' A child was described having a minute aberrant lingual thyroid only who presented clinically as intestinal obstruction ? congenital megacolon. Other instances of congenital thyroid deficiency presented in this way were referred to.

W. W. Payne (London). 'Apparatus and Method of Ultra Micro Chemical Techniques.' Description and demonstration.

\section{Erratum}

It is regretted that in the paper 'Observations on the Clinical Course and Treatment of One Hundred Cases of Still's Disease by B. E. Schlesinger, C. C. Forsyth, R. H. R. White, J. M. Smellie and C. E. Stroud, which appeared in this journal (Volume 36, pages 65-76) Figs. $9 a$ and $9 b$ were transposed. 